\title{
Exame do Cremesp como Indicador da Qualidade do Ensino Médico
}

\author{
The São Paulo State Regional Medical Council \\ Exam as an Indicator of Quality in Medical \\ Education
}

\author{
PALAVRAS-CHAVE \\ - Ética; \\ - Educação Médica; \\ - Avaliação de Serviços \\ de Saúde; \\ - Medicina.
}

Recebido em: 20/08/2013

Aprovado em: 07/11/2013

\author{
Alice Motal \\ Beatriz Carvalho \\ Ludmilla Candido ${ }^{I}$ \\ Raisa Lomanto \\ Thaís Maia
}

\begin{abstract}
RESUMO
Introdução: $O$ Brasil vive um período de crescimento do número de escolas médicas, atrelado à redução da qualidade do ensino, estruturas universitárias e hospitalares precárias e alunos mal preparados para a prática médica. Em 2012, o exame do Conselho Regional de Medicina do Estado de São Paulo (Cremesp) tornou-se obrigatório para a obtenção de registro profissional. Dos recém-formados em São Paulo, $54 \%$ tiveram escore insuficiente após responder a questões correspondentes às áreas básicas da medicina. Objetivo: Avaliar fatores relacionados ao mau desempenho dos recém-formados no exame do Cremesp em 2012. Metodologia: Foi realizada revisão bibliográfica a partir de fontes dos bancos Bireme, Scielo, PubMed $e$ do site do Cremesp. "Escolas médicas" e "educação médica" foram os descritores em ciências da saúde utilizados. A reportagem intitulada " $54,5 \%$ dos recém-formados em Medicina foram reprovados no exame do Cremesp" foi a base para o trabalho. De março a abril de 2013, analisaram-se artigos publicados a partir de 2007. Resultados: Na última década, o número de médicos aumentou $21 \%$, enquanto a população geral cresceu apenas 12\%. Cerca de 63\% dos alunos que realizaram o exame do Cremesp em 2012 avaliaram que o curso de Medicina deveria ser mais exigente. Pelo menos 16 faculdades de Medicina obtiveram, por três anos consecutivos, conceitos sofrível ou ruim no Enade. Em estudo desenvolvido entre acadêmicos de Medicina, $39 \%$ dos universitários dedicavam oito horas semanais ou mais a atividades extracurriculares. A precariedade do ensino médico brasileiro tem causas multifatoriais. Isto pode interferir no aumento do número de casos de iatrogenia e no questionamento sobre a necessidade de implantar outros métodos de avaliação do ensino médico, como testes de progresso. É preciso, portanto, compreender que uma educação médica de qualidade contribui para que os avanços econômicos caminhem pari passu com os sociais, sendo necessário repensar o modelo vigente para direcionar a vontade política e a gestão adequada de investimentos.
\end{abstract}

\begin{abstract}
Introduction: Brazil is currently undergoing a period of growth in the number of its medical schools, accompanied by a reduction in the quality of teaching, precarious university and hospital installations and students who are poorly equipped for medical practice. In 2012, passing the exam set by the São Paulo State Regional Medical Council (Cremesp) became a requisite for obtaining a medical license. Of São Paulo's recent graduates, $54 \%$ received an unsatisfactory score for their answers to the questions on the basic fields of medicine. Objective: To assess factors related to the low performance of these graduates in Cremesp's 2012 exam. Methodology: A bibliographical revision was undertaken based on data provided by Bireme, Scielo, PubMed and the Cremesp website. "Medical schools" and "medical education" were the terms used to describe health sciences. The report, entitled " $54.5 \%$ of recent medicine graduates failed the Cremesp exam" formed the basis of the work. From March to April 2013, articles published as of 2007 were analyzed. Results: In the previous decade, the number of doctors increased by $21 \%$, while the general population only increased by 12\%. Around 63\% of students to have taken the Cremesp exam in 2012 stated that the medical course should be more demanding. At least 16 medical faculties registered a low or poor performance in the National Exam for the Assessment of Student Performance (Enade) for three years running. In a study developed among medical academics, $39 \%$ of universities were revealed to dedicate eight hours per week or more to extra-curricular activities. The precarious nature of the teaching of medicine in Brazil is due to a variety of factors. This may impact the increase in the number of cases of iatrogenic infections or in the questioning of the need to implant other methods of assessing medical schools, as progress tests. We therefore must realize that quality medical education helps ensure economic advances match social advances, and must rethink the existing model in order to attract political will and the effective management of investments.
\end{abstract}




\section{INTRODUÇÃO}

A educação médica, à semelhança do sistema de saúde, tem sido questionada em todo o mundo. Em 1910, foi publicado o Relatório Flexner, mundialmente aceito como modelo de ensino na maioria das escolas médicas. Desde então, o programa acadêmico permaneceu praticamente inalterado, estando as ciências básicas claramente separadas do ciclo de estudos clínicos ${ }^{1}$. O modelo flexneriano, entretanto, demonstrou deficiências na formação humanística e crítica, não atendendo aos interesses da comunidade. $\mathrm{O}$ final do século XX caracterizou-se por maior inquietação de todos os componentes do sistema de saúde, incluindo profissionais, usuários e financiadores².

Apesar dos avanços da Medicina e da educação, o estágio alcançado pelo cuidado médico vem causando insatisfação geral. Esta se estende à educação médica, que, ao invés de propor a formação de médicos criativos e inovadores, utiliza uma abordagem eminentemente biomédica. A dificuldade de mudar o modelo de educação médica encontra barreiras, principalmente, em dois pontos ligados às próprias escolas médicas. Se, por um lado, vivenciamos a abertura indiscriminada de novas escolas de Medicina, por outro, temos a tradição de autonomia das escolas existentes. Tal situação acarretou a busca por novas formas de educar na saúde, com acréscimo de matérias como Epidemiologia, Psicologia, Antropologia e Comunicação Social2 ${ }^{2,3}$. Em 2001, o Ministério da Educação homologou as Diretrizes Curriculares Nacionais dos cursos de Medicina, objetivando uma formação médica que contemple as necessidades do Sistema Único de Saúde 3 . O processo de constituição profissional na área médica, focado na integralidade da saúde, contrasta fortemente com o modelo biomédico-fragmentário. Este último ainda é enraizado na educação brasileira, mesmo em um contexto de mudanças induzido pelo processo de agregação constante de conhecimento ${ }^{4}$.

A transição do modelo de formação médica teve início no regime militar, no auge do milagre econômico brasileiro, quando o governo apostou na abertura de vagas nas universidades em cursos de áreas consideradas chave para o País. Entre elas, estava a Medicina ${ }^{5}$. Foi então que ocorreu o primeiro grande boom de escolas médicas, com a criação, nesse período, de 39 faculdades de Medicina, sendo 23 delas na Região Sudeste ${ }^{5}$. A partir de 1996, houve o segundo boom, desta vez com predomínio de cursos privados. De 2000 a 2011, foram inaugurados 77 cursos médicos, dos quais 52 particulares. A perspectiva é que outras 20 escolas sejam inauguradas até 2014, continuando um crescimento exponencial que perdura há $40 \mathrm{anos}^{5}$. Na última década, o número de médicos aumentou $21,3 \%$, contrastando com o crescimento da população geral, que apresentou taxa de elevação de apenas 12,3\% ${ }^{5}$. Comparando-se com dados de
1970, o crescimento do número de médicos chegou a 2011 com um salto de $530 \%$, enquanto o da população brasileira significou $104,8 \%{ }^{5}$.

Nesse mesmo período, a percepção do empobrecimento da educação médica tem desencadeado medidas questionáveis, a exemplo da implantação do serviço civil voluntário para recém-formados tendo como contrapartida vantagens para o ingresso nos programas de residência médica e a flexibilização da revalidação de diplomas daqueles que se formaram no exterior ${ }^{5}$.

Os Conselhos de Medicina exercem o papel de disciplinadores da prática médica, cabendo a eles "zelar e trabalhar pelo perfeito desempenho ético da Medicina e pelo prestígio e bom conceito da profissão e dos que a exercem legalmente" (Lei 3.268/1957). Os Conselhos Regionais de Medicina (CRM) são os órgãos responsáveis por emitir a habilitação que autoriza o exercício da profissão e podem, portanto, exigir dos requerentes os documentos julgados necessários à complementação da inscrição no CRM. Tendo em vista a execução desse papel e o respaldo da lei, o Conselho Regional de Medicina do Estado de São Paulo (Cremesp) teve a iniciativa de realizar um exame de final de curso, diante da queda acentuada na qualidade do ensino médico ${ }^{6}$

Em 2005, foi realizado o primeiro exame do Cremesp, que teve caráter opcional e não interferiu na inscrição junto ao Conselho. A prova foi aplicada aos graduandos de escolas médicas paulistas e se tornou uma proposta inovadora de avaliação externa do ensino médico, deixando claro para a sociedade a atual precariedade da educação médica no Estado e a necessidade de seguir adiante com essa proposta. Os exames realizados durante esses sete anos revelaram que quase a metade dos graduandos sai das escolas despreparada, sem as mínimas condições de exercer a medicina ${ }^{6}$

A prova consta de 120 questões, cujo conteúdo abrange o diagnóstico ou tratamento adequado de problemas de saúde bastante frequentes, incluindo o atendimento em saúde mental, atendimento à gestante, em pronto-socorro, dentre outros. Abaixo de $60 \%$ de acertos, o resultado por área de conhecimento é considerado insatisfatório. Chama a atenção, na média dos sete anos, o baixo percentil de acertos em campos essenciais da Medicina, como Clínica Médica (54,9\% de acertos), Obstetrícia (58,5\%), Saúde Pública (58,8\%) e mesmo Pediatria (60\%), especialidades que estão entre as mais demandadas e concentram a solução de muitos problemas de saúde da população. Questões que tiveram baixa proporção de acertos revelam a falta de conhecimento dos participantes na solução de eventos frequentes no cotidiano da prática médica $^{6}$ 
No ano de 2012, em sua oitava edição, o exame tornou-se obrigatório para a obtenção do registro profissional, se estabelecendo como uma importante ferramenta do papel fiscalizador do Cremesp. O resultado obtido foi a reprovação de 54,5\% dos 2.411 recém-formados em escolas médicas paulistanas. Esses números causaram repercussão nacional nos meios de comunicação, levando ao alcance de um dos objetivos do Conselho: mobilizar a opinião pública. Embora a aprovação não seja um requisito necessário ao exercício da profissão, o exame é capaz de expor as deficiências e os méritos dos cursos e de seus alunos ${ }^{7}$

O objetivo do trabalho atual foi avaliar os fatores relacionados ao mau desempenho dos recém-formados no exame do Cremesp em 2012. Não há pretensão de esgotar o tema ou mesmo determinar solução para a falha do ensino médico, mas lançar sobre ele um olhar crítico, levantando discussões e gerando novas reflexões na comunidade médica.

\section{METODOLOGIA}

O ponto de partida para a reflexão apresentada encontra-se na reportagem intitulada " $54,5 \%$ dos recém-formados em Medicina foram reprovados no exame do Cremesp", publicada em dezembro de 2012 no Jornal do Cremesp. Esse artigo apresenta uma revisão bibliográfica a respeito do ensino médico no Brasil. Foram consultadas as fontes de referências bibliográficas dos bancos do Bireme, Scielo, PubMed central e o site do Cremesp. Utilizaram-se como descritores escolas médicas, educação médica, localizados nos descritores em ciências da saúde (DeCS). Foram analisados artigos publicados a partir do ano de 2007. O material levantado foi analisado pelos autores no período compreendido entre 19 de março e 9 de abril de 2013.

\section{DISCUSSÃO}

A precária qualidade do ensino médico brasileiro é influenciada por diversos fatores, desde a quantidade demasiada de escolas, sem definição de critérios mínimos e sem assegurar mecanismos adequados para garantir a qualidade da educação médica, até a necessidade de um currículo vasto, que influencie a dedicação dos alunos ao curso. No contexto de um sistema carente de melhor distribuição demográfica de profissionais, mais igualitária e adequada às necessidades da população, as consequências podem ser devastadoras: profissionais mal preparados e maior número de erros médicos, culminando em um desgaste da credibilidade da classe médica frente à sociedade. Tendo em vista essa situação, discutiremos os principais pontos envolvidos no quadro.

\section{Distribuição versus número atual dos médicos no Brasil}

A abertura desenfreada de escolas médicas nas últimas quatro décadas tem resultado em muitos profissionais formados no Brasil. Ainda assim, o governo tem considerado o País como carencial nesse setor. Avaliar a defasagem da saúde pública como quantitativa é insuficiente para orientar uma política de reordenamento da necessidade de médicos, uma vez que a demografia médica vai muito além dos números ${ }^{7}$. Como tem sido constatada, a presença de médicos em grande número em nível nacional ou mesmo regional é uma condição necessária, porém insuficiente, para garantir aos cidadãos o acesso verdadeiro aos cuidados de saúde 5 .

O Brasil nunca teve tantos médicos em atividade, mantendo-se alta nos últimos anos a taxa de crescimento do número de profissionais, maior que a da população geral. Além disso, a cota de entrada desses trabalhadores no mercado também permanece maior que a de saída, com o crescimento da média de anos de trabalho e redução da média de idade dos profissionais (perfil de trabalhadores mais jovens) ${ }^{5,8}$.

Segundo dados do IBGE de 2012, a distribuição dos médicos no País é acentuadamente divergente, tendo, por exemplo, o Distrito Federal uma relação de 4,09 profissionais por mil habitantes, enquanto no Maranhão esse número é de 0,71, índices comparáveis aos de países africanos. Entre as regiões, o Nordeste apresenta menor valor, com 1,23 médicos por mil habitantes, tendo o Brasil essa relação de dois profissionais / habitantes ${ }^{5,6}$. A Organização Mundial da Saúde (OMS) não preconiza número ideal de profissionais por habitantes, já que essa definição depende de múltiplos fatores ${ }^{5}$.

Além da diferença dos números de distribuição de médicos entre as regiões brasileiras, dentro dos próprios Estados essa divergência se faz presente. As metrópoles contam, em média, com até quatro vezes o número de profissionais comparando-se com regiões interioranas. Fazendo-se análise entre os médicos que atuam no Sistema Único de Saúde e aqueles que trabalham em setores privados, é notado pior desempenho numérico no SUS. É constatada uma demografia médica ainda mais excludente que a verificada nas desigualdades regionais. A clientela da saúde privada conta com 3,9 vezes mais postos de trabalho médico disponíveis que os usuários da rede pública. Na Bahia, a diferença entre os setores públicos e privados é alarmante. Aqueles que só têm acesso à saúde pública - que representam $89,7 \%$ da população desse Estado - contam com 12,11 vezes menos postos de trabalho médico ocupados que seus vizinhos de planos de saúde. Esse fosso pode ocorrer dentro de um mesmo município. Sem uma política eficaz de presença do Estado, de atração e de valoriza- 
ção dos médicos nessas regiões menos assistidas, é presumível que o aumento do efetivo médico acentuará ainda mais as desigualdades da distribuição dos profissionais ${ }^{1}$.

De toda a população médica brasileira, $45 \%$ são formados por médicos generalistas. Esse contingente de profissionais sem especialização, parte deles com larga experiência profissional, pode ser considerado um fator positivo para o sistema de saúde brasileiro e até, eventualmente, um elemento regulador da diminuição de desigualdades na demografia médica ${ }^{5}$.

Em números absolutos, o Brasil apresenta a quinta maior população de médicos do planeta, atrás somente da China, Estados Unidos, Índia e Rússia. Os médicos brasileiros representam, sozinhos, $4 \%$ da população médica mundial e 19\% dos médicos de toda a região das Américas. Com esses valores, o esperado pela OMS seria que o País tivesse adequados atendimento e assistência à população. Entretanto, o Brasil vive uma situação inversa. Os gastos públicos representam $45 \%$, para cobertura de toda a população dependente do SUS, contra $55 \%$ do privado, que atende apenas um quarto da população. Sem alterar essa equação, políticas indutoras de formação de mais médicos não surtirão o efeito desejado de oferecer melhor assistência em saúde para toda a população ${ }^{5}$.

São necessárias mudanças estruturais no sistema de saúde. O Brasil não precisa de mais médicos, carece de melhor gestão e distribuição justa entre as regiões e setores público e privado ${ }^{9}$. As desigualdades não se resolverão com mais vagas e com novos cursos de Medicina. $\mathrm{O}$ governo federal tem demonstrado preferir quantidade a qualidade de médicos no Brasil $^{8}$

\section{Perfil dos Alunos que Prestaram o Exame}

Durante os exames não obrigatórios realizados pelo Cremesp de 2005 a 2012, foi traçado um perfil dos estudantes participantes. Destes, $87 \%$ são brancos, de classe média e alta, sendo que $49 \%$ têm renda familiar acima de 21 salários mínimos. Mais de $73 \%$ não exercem ou exerceram atividade remunerada, tendo seus gastos custeados pela família. Aproximadamente $85 \%$ estudaram em escolas privadas, $37 \%$ fizeram curso preparatório para o vestibular por um período igual ou superior a dois anos e $77 \%$ têm pais e $65 \%$ mães com nível superior. Ainda entre esses universitários, $83 \%$ dominam o idioma inglês, cerca de $60 \%$ deles vai pouco ou raramente a cinema e teatro, e menos de um terço lê jornais e revistas com frequência. $O$ perfil traçado com as informações obtidas dos graduandos constata um grupo com características privilegiadas, que pode ser estendido à maioria dos estudantes do curso de Medicina do Estado de São Paulo e parte do País. Advindos de famílias com nível universitário, com passagem por colégios particulares, esses estudantes têm histórico escolar diferenciado e formam um grupo de elite dentro da universidade, podendo se dedicar em período integral aos estudos?

Esse cenário explica por que estes estudantes foram aprovados nos exames de vestibular dos cursos de Medicina em São Paulo, que estão entre os mais disputados do Brasil. Entretanto, este mesmo perfil socioeconômico e cultural elevado não é condizente com o baixo rendimento no exame do Cremesp. Ainda pode-se aventar que, pelo caráter voluntário do exame dos anos anteriores a 2012, os estudantes que optaram por realizá-lo são os que se sentiam mais preparados. Tais resultados levam à constatação de que as falhas podem estar atreladas ao ensino médico de má qualidade, e não ao desempenho pessoal dos alunos. Essa tese é reforçada por outra conclusão da pesquisa: $63 \%$ dos alunos avaliaram que o curso de Medicina deveria ter sido mais exigente durante a graduação ${ }^{7}$

\section{Desempenho Baixo em Áreas Básicas}

Segundo o Conselho Federal de Medicina (CFM), a iniciativa do Cremesp de realizar o exame configura um instrumento metodológico relevante para mensurar, de forma quantitativa, o nível do conhecimento obtido pelos egressos das escolas de Medicina ${ }^{7}$. Nesse contexto, foi observado que, em quatro dos sete exames realizados pelo Cremesp, entre os anos de 2005 a 2011, mais da metade dos estudantes foram reprovados, o que foi considerada uma tendência insatisfatória e preocupante ${ }^{6}$

A notícia de que $54,5 \%$ dos participantes acertaram menos de $60 \%$ das questões no último exame, o primeiro obrigatório para a obtenção do CRM, mostrou que, pelos critérios do Cremesp, mais da metade dos egressos de escolas médicas de São Paulo não estão preparados para o exercício da profissão ${ }^{6}$. Questões que tiveram baixa proporção de acertos revelam a falta de conhecimento dos participantes na solução de eventos frequentes no cotidiano da prática médica. Para o Cremesp, muitas questões com alto índice de erro tratavam de situações habituais, que exigiam habilidades fundamentais esperadas de um médico após a graduação, de acordo com as Diretrizes Curriculares Nacionais ${ }^{6}$. O desempenho nas áreas básicas da medicina é preocupante: na média dos sete anos, houve baixo percentil de acertos em campos essenciais, como Clínica Médica (média de 54,9\% de acertos), Obstetrícia (58,5\%), Saúde Pública $(58,8 \%)$ e mesmo Pediatria (60\%), especialidades que estão entre as mais demandadas e concentram a solução de muitos problemas de saúde da população. 
TABELA 1

Média de acertos por área de conhecimento no exame do Cremesp de 2005 a 2011

\begin{tabular}{|c|c|c|c|c|c|c|c|c|}
\hline \multirow{2}{*}{$\begin{array}{c}\text { Áreas de } \\
\text { conhecimento }\end{array}$} & \multicolumn{7}{|c|}{ Exame } & \multirow{2}{*}{$\begin{array}{c}\text { Média dos } \\
\text { sete anos }\end{array}$} \\
\hline & 2011 & 2010 & 2009 & 2008 & 2007 & 2006 & 2005 & \\
\hline Saúde Pública & 49,0 & 54,8 & 60,7 & 66,6 & 72,3 & 67,5 & 40,6 & 58,8 \\
\hline Obstetrícia & 54,1 & 64,7 & 62,6 & 53,9 & 58,9 & 56,1 & 59,3 & 58,5 \\
\hline Clínica Médica & 56,5 & 56,8 & 48,4 & 56,7 & 50,0 & 60,8 & 55,2 & 54,9 \\
\hline Pediatria & 59,3 & 64,5 & 57,0 & 51,3 & 50,4 & 63,6 & 73,9 & 60,0 \\
\hline $\begin{array}{l}\text { Clínica } \\
\text { Cirúrgica }\end{array}$ & 65,2 & 66,5 & 53,7 & 58,3 & 53,8 & 58,5 & 67,5 & 60,5 \\
\hline $\begin{array}{l}\text { Ciências } \\
\text { Básicas }\end{array}$ & 65,3 & 54,1 & 55,4 & 52,3 & 55,6 & 62,6 & 68,7 & 59,1 \\
\hline Saúde Mental & 67,3 & 69,8 & 51,2 & 83,1 & 63,6 & 58,6 & 68,4 & 66,0 \\
\hline Ginecologia & 69,8 & 65,6 & 69,0 & 52,0 & 49,1 & 64,8 & 65,2 & 62,2 \\
\hline Bioética & 78,2 & 71,9 & 85,7 & 74,1 & 70,0 & 71,2 & 62,8 & 73,4 \\
\hline
\end{tabular}

Fonte: Exame do Cremesp agora é obrigatório, p. 11. Cremesp, São Paulo, 2012.

Infelizmente, os resultados alcançados confirmam a suposição de que a qualidade da formação oferecida está abaixo do desejável, realidade constatada em São Paulo e que o CFM acredita ser a mesma em todos os Estados ${ }^{7}$.

\section{Enade como Marcador de Precariedade na Infraestrutura das Escolas Médicas}

A acessibilidade ao ensino de graduação cresceu nos últimos anos e tem atingido um amplo espectro da população, fato que tem acompanhado as exigências do mercado de trabalho. Isto se refletiu na abertura desenfreada de instituições provedoras de ensino de qualidade questionável no Brasil. Segundo artigo publicado em jornal, um terço das faculdades brasileiras foi reprovado na avaliação do MEC no ano de 2012. Das 1.516 faculdades avaliadas no País, 531 conseguiram conceito 1 (sofrível) ou 2 (ruim) na nota do Exame Nacional de Desempenho de Estudantes (Enade) $)^{10}$. O conceito do Enade é mensurado por meio da nota, que corresponde a $30 \%$, da titulação dos professores e seu regime laboral (vale 15\%) e dos índices de infraestrutura e organização didático-pedagógica da instituição $(15 \%)^{10}$

A realidade das escolas médicas parece seguir a mesma tendência das faculdades como um todo, mesmo apresentando dados mais discretos. Existem pelo menos 16 faculdades de Medicina que por três anos consecutivos obtiveram conceitos 1 e 2 no Enade ${ }^{11}$. Em 2012, o MEC chegou a descredenciar quatro instituições privadas, e algumas destas faculdades não possuíam sequer prática ${ }^{12}$

A proliferação de escolas médicas tem se agravado com a implantação, em 2012, do Plano Nacional de Educação Mé- dica, lançado pelo governo, que pretende aumentar em 4.500 o número de médicos formados por ano ${ }^{4}$. Problemas como falta de laboratórios, bibliotecas e hospitais para aprendizado acompanharam a proliferação das faculdades, tornando prioritário o investimento nos cursos já existentes no País em detrimento da abertura de novos $\operatorname{cursos}^{13}$ Em 2013, o MEC interveio em uma faculdade particular tradicional do Rio de Janeiro. O ministério já havia sido notificado da precariedade das condições das práticas de ensino, entretanto sugeriu que os estudantes recorressem a órgãos de Defesa do Consumidor. Tal decisão torna-se contrastante, pois medidas como facilitação da entrada de médicos do exterior no Brasil estão sendo tomadas, ao mesmo tempo em que não há cuidado com as escolas de Medicina que existem no país ${ }^{14}$ Essa má infraestrutura se reflete na qualidade de ensino e certamente tem influenciado os resultados do exame do Cremesp observados nos últimos tempos.

\section{Fatores Extracurriculares e Dedicação ao Curso de Medicina}

O desenvolvimento da educação e da própria ciência que vem sendo observado nas últimas décadas exige profissionais cada vez mais especializados. O currículo mais volumoso, por vezes, é sinônimo de maior qualidade, exigindo do estudante de Medicina a especialização ainda dentro da universidade. Este comportamento vai de encontro às Diretrizes Nacionais do Ensino Médico e à discussão atual sobre a necessidade de formar médicos generalistas para atuar no SUS ${ }^{15}$.

O estudante de Medicina sente-se impelido a participar de atividades extracurriculares, como ligas acadêmicas, monitoria, pesquisa, estágio e congressos. Tudo isso, ao compor um 
bom currículo, torna-se essencial para que o futuro médico consiga uma vaga em uma boa residência, aspiração ainda hegemônica. Cabe ressaltar que o discente se espelha no docente, que possui realidade semelhante em termos de exigências. Em geral, ao lado das atividades de ensino, há grande sobrecarga de atividades administrativas, além da enorme pressão por produtividade científica ${ }^{16}$.

Em estudo realizado sobre atividades extracurriculares, por meio de inquérito realizado com estudantes de Medicina, os autores observaram que os alunos que participavam dessas atividades desenvolviam várias delas simultaneamente e que a participação em ligas acadêmicas era a mais frequente ${ }^{17}$. Em outro estudo desenvolvido entre alunos de ciências médicas da Faculdade de Medicina de Ribeirão Preto - Universidade de São Paulo, a maioria (39\%) dedicava oito horas ou mais a atividades extracurriculares. A maioria (52,2\%) fazia entre duas e três atividades. Quanto aos motivos para realizá-las, $54 \%$ foram justificadas por afinidade, $21 \%$ por serem importantes para complementar o curso médico, 9,5\% pela importância curricular, 2,2\% porque são remuneradas, 2,3\% devido à influência de conhecidos e $11 \%$ por outros motivos, como lazer, melhorar a saúde, curiosidade e socializar ${ }^{18}$.

Atividades extracurriculares trazem experiências positivas para o estudante ao contribuírem para que ele se sinta parte de um grupo social, com identidade própria, tratando-se de um mecanismo de adaptação do indivíduo ao curso médi$\mathrm{Co}^{19}$ Entretanto, a supervalorização do currículo paralelo deve ser questionada quando interfere negativamente no currículo tradicional proposto pela universidade. Sabe-se que há elevada exigência ao estudante de Medicina. Ele é submetido a uma carga horária extenuante e sobrecarga de assuntos. Além disso, o pouco tempo livre disponível é despendido em atividades extracurriculares. Ao considerar as atividades não obrigatórias como necessidade de complementar o curso médico, poderia se inferir que toda a exigência do currículo tradicional estaria sendo devidamente suprida, porém esta realidade não tem sido observada nos resultados dos exames dos recém-formados.

\section{Iatrogenia e Educação Médica}

Nos últimos anos, tem-se observado um aumento do número de denúncias contra médicos nos Conselhos Regionais de Medicina (CRM), sendo o erro médico, aliado a uma relação médico-paciente insatisfatória, o responsável por grande parte de$\operatorname{las}^{20}$. Segundo o Código de Ética Médica, o erro médico pode ser classificado como imperícia, quando o médico realiza um procedimento para o qual não está habilitado; imprudência, quando age sem cautela; ou negligência, quando não oferece os cuidados necessários ao paciente ${ }^{21,22}$. A negligência aparece como causa principal entre as denúncias, demonstrando que as falhas no exercício profissional do médico se devem, principalmente, à omissão ou à passividade do profissional frente a seus pacientes ${ }^{23}$. Os erros médicos, tais como os conhecemos no CEM, se enquadram na categoria de iatrogenias ${ }^{24}$.

Dentre os principais fatores que geram esse quadro, estão a deterioração da relação médico-paciente e a formação deficiente de médicos durante a graduação ${ }^{21}$. Segundo relatório da Comissão Interinstitucional de Avaliação do Ensino Médico (Cinaem), as escolas médicas brasileira estão formando profissionais que não atendem às demandas da população. Os médicos recém-formados saem das faculdades com uma formação ética e humanística deficiente, uma concepção funcionalista do processo saúde-doença, especialização precoce e incapazes de se manter atualizados ${ }^{25,26}$. A insatisfatória formação ética do médico contribui para a ocorrência de desvios na conduta durante o exercício da profissão. Estes desvios ocorrem, principalmente, em desfavor da população de mais baixa renda, uma vez que o sistema público de saúde oferece recursos técnicos precários e, sobretudo, uma demanda sufocante para o médico, criando as condições ideais para o ato médico adverso ${ }^{27,28}$.

Há ainda outro ponto, no âmbito da formação acadêmica, a ser abordado: a constituição da identidade do médico. A começar pela decisão com relação ao curso, que ocorre num momento de conflitos, podendo a vocação médica ser sobrepujada por outros interesses, como a busca de reconhecimento e prestígio social, satisfação dos desejos dos pais e ganho financeiro. Nesse caso, falsas vocações podem culminar em identidades frágeis, hostis, erradias, logo iatrogênicas. Além disso, grande parte dos processos seletivos das escolas médicas brasileiras prioriza a memorização, constituindo um método de avaliação falho, que aprova indivíduos inaptos para lidar com frustrações, paciência, perseverança e dedicação, que são capacidades necessárias a um futuro médico ${ }^{24}$

Nesse contexto, a educação médica tem dois papéis: o de informador, fornecendo ao estudante conhecimentos científicos e técnicos essenciais ao exercício da futura profissão, e o de formador, como responsável pelo amadurecimento de uma personalidade adulta e equilibrada, capaz de entender a complexa estrutura biopsicossocial do paciente ${ }^{29,30}$. Desse modo, a educação médica tem papel relevante na profilaxia de eventos iatrogênicos, sendo necessário estimular, desde a graduação, discussões que visem formar profissionais mais comprometidos com a prática médica e menos sujeitos a esse tipo de problema, prevenindo erros $24,31,32$. 


\section{Teste de Progresso}

Diante do alto índice de reprovação observado no exame do Cremesp (46,7\% de 2005 a 2011) ${ }^{6}$, considerando, assim, uma parcela significativa dos recém-formados inapta ao exercício da profissão, algumas alternativas foram propostas para corrigir as deficiências demonstradas pelos recém-graduados no exame. Um exemplo foi o idealizado, após o anúncio da obrigatoriedade do exame, pelo ex-ministro da Saúde Adib Jatene. Assim como outras personalidades e instituições ligadas à medicina, ele apoia declaradamente o caráter obrigatório da avaliação e sugeriu que, além do exame do Cremesp, se implementasse uma avaliação externa durante o curso ${ }^{33}$.

Jatene propõe realizar os testes a cada dois anos ao longo do curso médico, caracterizando um teste de progresso. Se ao final do segundo ano o resultado do exame evidenciar uma formação inadequada dos alunos, a escola deveria ter o vestibular suspenso no ano seguinte, dando tempo hábil, segundo ele, para as correções cabíveis à instituição e/ou a seu método de ensino ${ }^{33}$. A ideia de avaliar não somente os egressos do curso, mas também os estudantes no decorrer da formação médica constituiria mais uma ferramenta em busca de um controle da qualidade do ensino e aprendizado da medicina.

\section{Reprovação Impeditiva}

Atualmente, o exame do Cremesp tem caráter obrigatório, sendo a participação na prova uma exigência para a aquisição do registro profissional no Estado de São Paulo, obedecendo à Resolução Cremesp nº 239, de 25 de julho de 20127 . Embora haja essa regulamentação, a reprovação ou mau desempenho no exame não constituem critérios impeditivos à obtenção do registro ${ }^{6}$, uma vez que este é um direito, garantido por lei, dos médicos portadores de diploma de graduação ${ }^{34}$. Tais circunstâncias dão espaço para o questionamento quanto ao real esforço e estudos que os graduandos dedicam à realização da prova, pensada inicialmente como teste de proficiência, isto é, de competência, habilidade e, principalmente, conhecimento — primordialmente básicos ${ }^{6}$.

Os resultados foram insatisfatórios desde a implementação do exame e trouxeram à tona a inquestionável necessidade de repensar a qualidade do ensino médico. Os baixos índices de aprovação suscitam a discussão da possível interferência de outros fatores no desempenho apresentado, a exemplo de uma provável displicência no momento de responder às questões, gerada pela conjuntura citada. Essa indiferença quanto ao resultado pode reverberar nas notas apresentadas, contribuindo, em parte, para os resultados que traduzem a inaptidão para o exercício profissional de grande parte dos egressos das escolas médicas paulistas.
Desde que foi anunciada a obrigatoriedade do exame, o Cremesp recebeu expressivo apoio de personalidades e entidades ligadas à medicina e à sociedade pela iniciativa, pioneira no País ${ }^{33}$. Muitas das opiniões apoiam, inclusive, que o exame se torne impeditivo, servindo como um filtro de mercado, de modo a evitar que médicos inaptos exerçam a profissão, defendendo, desta forma, o interesse primordial no exercício desta, que é a excelência no atendimento às necessidades sociais. No entanto, o Conselho não tem autonomia para condicionar o registro à aprovação em uma prova. Para que isso ocorra, é necessária uma lei federal semelhante à que instituiu o exame da $\mathrm{OAB}$, o que está em tramitação no Congresso Nacional ${ }^{7}$. Caso isso ocorra, o exame poderá servir como uma ferramenta do Conselho para proteger os próprios membros da classe, que vêm perdendo prestígio em razão da atuação desastrosa de profissionais desqualificados.

\section{CONSIDERAÇÕES FINAIS}

Como consta no Código de Ética Médica, resolução do CFM $\mathrm{n}^{\circ} 1.931 / 09$, capítulo de responsabilidade profissional, é vedado ao médico causar dano ao paciente, por acaso ou omissão; delegar a outros profissionais atos ou atribuições exclusivos da profissão médica; deixar de assumir responsabilidade sobre procedimento que indicou ou de que participou; deixar de esclarecer o paciente sobre determinantes sociais ou profissionais de sua doença, entre outras situações. Todos esses delitos, e muitos outros, tornam-se mais propensos a acontecer quando se tem uma educação médica de baixa qualidade.

O ensino médico no Brasil vem sendo criticado há alguns anos, e as evidências desse decaimento estão explicitadas de diferentes formas. Escândalos de erros médicos aparecem como notícias na mídia; o número de processos contra médicos por má prática e infrações éticas cresce vertiginosamente; muitos recém-formados não conseguem passar nas disputadas provas de residência, e outros tantos, quando o fazem, contam com a ajuda de cursos preparatórios. Tais cursos não seriam necessários caso as universidades suprissem o ensino com a grade curricular de forma adequada. Logo, o fato de serem considerados indispensáveis pelos alunos de quinto e sexto anos demonstra a insuficiência e inadequação do conteúdo disciplinar das escolas médicas.

Mais recente e alarmante é o mau desempenho dos médicos recém-formados de São Paulo nos exames do Cremesp dos últimos sete anos, com resultados preocupantes em matérias básicas, nota final insatisfatória e erros em casos comuns de prática médica. Frente a essas situações, torna-se urgente a 
necessidade de discutir e propor mudanças para a situação do ensino médico brasileiro.

Atualmente, a formação acadêmica é deficiente sob diversos ângulos: questiona-se a qualidade de ensino, bem como seus métodos, a dedicação excessiva à abordagem organicista e fragmentada do paciente e a especialidade precoce, dentre outros fatores. Com isso, boa parte das escolas é incapaz de promover uma formação generalista, humanista, crítica e reflexiva em todos os níveis de atenção à saúde, formando médicos sem competências e habilidades nas diversas áreas do conhecimento médico, notadamente nas especialidades básicas, como demonstra o resultado do exame.

Como agravante da situação, o governo anunciou, em 2012, a intenção de criar outras 2.500 vagas de Medicina no Brasil, como forma de reduzir uma suposta carência de médicos no País. Entretanto, como demonstrado neste artigo, o problema não está na falta de profissionais: há um número de médicos suficiente no território brasileiro, mas estes estão distribuídos de forma desigual e excludente, tanto entre as regiões como entre setores público e privado. A escassez de médicos em algumas regiões, como Norte e Nordeste, bem como no setor público, levou o governo a crer que, criando novas universidades, esse problema seria sanado. No entanto, trata-se de uma medida simplista, que tem sucateado o ensino e, consequentemente, desqualificado os recém-formados.

Tendo em vista o papel relevante da educação médica na formação de profissionais competentes e bem preparados e na profilaxia de erros médicos, temas como ética médica, relação médico-paciente e iatrogenia devem compor a grade curricular do curso, e não constarem somente na pauta dos educadores de pós-graduação ou estarem dispersos em algumas disciplinas, como Psicologia Médica.

Os resultados do exame do Cremesp sinalizam as inúmeras deficiências do ensino médico, representando uma amostra que reflete a realidade nacional. Sendo assim, é necessário repensar diversos pontos e interesses sociais, econômicos e educacionais no que tange ao direito da população de ser assistida integralmente por profissionais bem qualificados.

Somente com vontade política, financiamento adequado e gestão qualificada poderá haver uma mudança da situação em que se encontra o ensino médico brasileiro. Para isso, é preciso que o governo demonstre a compreensão de que o investimento em saúde - assim como em educação - coloca o cidadão como fim maior de sua existência, provando que no País o desenvolvimento econômico andará de braços dados com os avanços sociais.

\section{REFERÊNCIAS}

1. Pagliosa FR, Da Ros MA. Relatório Flexner: Para o bem e para o mal. Revista Brasileira de Educação Médica 2008; 32(4):492-499.

2. Peixinho AL. Educação Médica - O Desafio de sua Transformação. Salvador; 2001. Mestrado [Dissertação] - Universidade Federal da Bahia.

3. Aguiar AC, Ribeiro ECO. Conceito e Avaliação de Habilidades e Competência na Educação Médica: Percepções Atuais dos Especialistas. Revista Brasileira de Educação Médica 2010; 34 (3): 371-378.

4. Oliveira NA. Ensino Médico no Brasil: Desafios e prioridades, no contexto do SUS - um estudo a partir de seis estados brasileiros. Rio de Janeiro; 2007. Mestrado [Dissertação] - Instituto Oswaldo Cruz.

5. Conselho Federal de Medicina. Demografia Brasileira, Dados gerais e descrições de desigualdades. Cremesp, Vol. 1. Relatório de pesquisa - Dezembro de 2011.

6. Cremesp. Exame do Cremesp obrigatório para registro profissional de médicos; 2012.

7. Damante N, Silvestre A, editores. $54 \%$ dos recém-formados em Medicina foram reprovados no Exame do Cremesp. Jornal do Cremesp 2012 Dez; ed no 299.

8. Bonamigo JC. Jornal Folha de São Paulo [www.folha.uol. com.br]. A qualidade dos médicos no Brasil [capturado 4 abr 2013]. Disponível em: http://www1.folha.uol.com. br/fsp/opiniao/63321-a-qualidade-dos-medicos-no-brasil.shtml

9. Brasil. Ministério do Planejamento, Orçamento e Gestão. Instituto Brasileiro de Geografia e Estatística. Contagem populacional. [capturado mar.2013]

10. Mendes V, Balmante O, Lira D. Escolas Médicas [www. escolasmedicas.com.br]. MEC reprova um terço das faculdades do País Instituições obtiveram nota 1 ou 2 numa escala que vai até 5 e receberão punição [capturado 3 abr 2013]. Disponível em: http://www.escolasmedicas.com. br/news_det.php?cod=1718.

11. Bocchini B. MEC tem responsabilidade pelo fraco desempenho de formandos [capturado 4 abr 2013]. Disponível em http://agenciabrasil.ebc.com.br/noticia/2012-12-07/ cremesp-mec-tem-responsabilidade-pelo-fraco-desempenho-de-formandos-de-medicina

12. CEMERJ [www.cremerj.org.br]. CREMERJ apoia proposta de intervenção da Gama Filho/RJ [capturado 4 abr 2013]. Disponível em: http://www.cremerj.org.br/informes / mostra.php?id=1750

13. Collucci C. Escolas Médicas [www.escolasmedicas.com. br]. Prioridade deveria ser o investimento na qualidade 
dos cursos existentes [capturado 3 abr 2013]. Disponível em: http://www.escolasmedicas.com.br/news_det. php?cod $=1745$

14. Tokarnia M. Agência Brasil [www.agenciabrasil.ebc.com. br]. Secretário diz que fechar instituições não é objetivo, e sim garantir qualidade do ensino superior [acesso em 03 de abril de 2013]. Disponível em: http:/ /agenciabrasil. ebc.com.br/noticia/2013-01-21/secretario-diz-que-fechar-instituicoes-nao-e-objetivo-e-sim-garantir-qualidade-do-ensino-superior

15. Torres AR, Oliveira GM, Yamamoto FM, Lima MCP. Ligas Acadêmicas e formação médica: contribuições e desafios. Interface - Comunic., Saúde, Educ. 2008;12(27):713-20.

16. Fernandes CMB. Docência universitária e os desafios da formação pedagógica. Interface - Comunic. Saúde, Educ. $2001 ; 9(2): 177-82$.

17. Peres CM, Andrade AS. Atividades extracurriculares: representações e vivências durante a formação médica. Ribeirão Preto; 2005. Mestrado [Dissertação] - Universidade de São Paulo; 2005.

18. Vieira EM, Barbieri CLA, Vilela DB, Júnior EI, Tomé FS, Woida FM, et al. O que eles fazem depois da aula? As atividades extracurriculares dos alunos de ciências médicas da FMRP-USP*. Medicina Ribeirão Preto 2004; 37:84-90.

19. Meleiro AMAS. O médico como paciente. São Paulo: Lemos Editorial; 1999.

20. D’Acampora AJ, Corrêa G. Erro médico, uma abordagem. Acta Cir Bras. 1996;11(1):42-6.

21. Kfouri Neto M. Responsabilidade civil do médico. 3 ed. São Paulo: Ed. Revista de Tribunais; 1999.

22. Conselho Federal de Medicina. Resolução CFM $n^{\circ}$ 1246/1988. Código de Ética Médica. Diário Oficial da União. Brasília, DF, 26 jan. 1988.

23. Bitencourt AGV, Neves NMBC, Neves FBCS, Santos LSCS. Análise do Erro Médico em Processos Ético-Profissionais: Implicações na Educação Médica. Revista Brasileira de Educação Médica 2007; 31(3): 223-228.

24. Tavares FM. Reflexões acerca da Iatrogenia e Educação Médica. Revista Brasileira de Educação Médica 2007; 31(2):180-185.

25. Comissão Interinstitucional Nacional de Avaliação do Ensino Médico. Avaliação do ensino médico no Brasil, entre 1991 e 1997: relatório geral. Brasília; 1997.

26. Rego S. A formação ética dos médicos: saindo da adolescência com a vida (dos outros) nas mãos. Rio de Janeiro: Ed. FIOCRUZ; 2003.

27. Gomes JCM. O atual ensino da ética para os profissionais de saúde e seus reflexos no cotidiano do povo brasileiro. Bioetica. 1996; 4(1):53-64.
28. Lampert JB. Tendências de mudanças na formação médica no Brasil: tipologia das escolas. São Paulo: Hucitec; 2002.

29. Gonçalves EL. Evolução do ingressante da escola médica do Brasil com vistas ao atendimento das necessidades da comunidade brasileira. Rev Bras Educ Med. 1990; 14(13): $17-9$

30. Ambrósio MR, Spíndola EB, Santos GT, Paiva HCF, Pacheco LF, Patrocínio LG, et al. Exercício profissional da medicina por estudantes. Rev Bras Educ Med. 2001; 25(3): 28-38.

31. Lester H, Tritter JQ. Medical error: a discussion of the medical construction of error and suggestions for reforms of medical education to decrease error. Med Educ. 2001; 35(9): 855-61.

32. Estrada CA, Carter J, Brooks C, Jobe AC. Medical errors must be discussed during medical education. BMJ. 2000;321(7259): 507-8.

33. Cremesp [www.cremesp.org.br]. Entidades e personalidades expressam apoio e manifestam o que pensam sobre a iniciativa do Cremesp [acesso em 01 de abril de 2013]. Disponível em: http:/ / www.cremesp.org. $\mathrm{br} /$ ? siteAcao $=$ NoticiasC $\& \mathrm{id}=2577$

34. Brasil. Lei no 3.268 , de 30 de setembro de 1957. Dispõe sobre os Conselhos de Medicina, e dá outras providências. Diário Oficial da União, 01 out 1957. Seção 1, Página 23013.

\section{CONTRIBUIÇÃO DOS AUTORES}

Todos os autores participaram de formal igual e conjunta no desenvolvimento do presente trabalho, desde a revisão bibliográfica até a formatação do mesmo.

\section{CONFLITO DE INTERESSES}

Em consonância com os termos do Art. 109 do Código de Ética Médica, os autores deste trabalho declaram que não possuem interesses pessoais, comerciais, acadêmicos, políticos ou financeiros e que não houve apoio financeiro nem material para a realização deste trabalho. Todos os autores participaram de forma suficiente na concepção e desenho do estudo, assim como da análise e interpretação dos dados e da redação do texto, podendo assumir a autoria e a responsabilidade pública pelo conteúdo deste artigo. Destaca-se o aprofundamento dos autores nos seguintes temas:

Alice Mota: "Enade como marcador de precariedade na infraestrutura das Escolas Médicas" e "Fatores extracurriculares e dedicação ao curso de medicina".

Beatriz Carvalho: "Desempenho baixo em áreas básicas". Ludmila Candido: "Teste do progresso".

Raisa Lomanto: "Distribuição atual dos médicos no Brasil" e "Perfil dos alunos que prestaram o exame". 
Thaís Maia: "Iatrogenia e educação médica" e "Reprovação impeditiva".

A versão final deste artigo foi lida e aprovada pelos cinco autores para ser encaminhado à publicação.

\section{ENDEREÇO PARA CORRESPONDÊNCIA}

Thaís Maia

Rua Santa Rita de Cássia, número 220, Casa.

Graça - Salvador

CEP: 40150-10 - BA

E-mail: thaismaiamb@gmail.com 